\title{
As representações do cinema lésbico no jornal Diario de Pernambuco (2016-2020)
}

\section{Las representaciones del cine lesbiano en el periódico Diario de}

Pernambuco (2016-2020)

\section{The representations of the lesbian cinema in the newspaper Diario de}

\author{
Pernambuco (2016-2020)
}

\author{
Ana Maria dos Santos Costa ${ }^{1}$ \\ Kalina Vanderlei Silva ${ }^{2}$
}

\begin{abstract}
Resumo
O presente artigo tem como objetivo analisar as representações sobre filmes com temática lésbica construídas pelo jornal recifense Diario de Pernambuco entre 2016 e início de 2020. Para tanto, focalizará resenhas críticas publicadas concomitantemente aos lançamentos de três filmes de diferentes nacionalidades: Carol (2015), dirigido por Todd Haynes, Rafiki (2018), de Wanuri Kahiu e Retrato de Uma Jovem em Chamas (2019), de Céline Sciamma. Considerando os contextos de produção e recepção das matérias e das obras cinematográficas, o artigo procura as representações sobre mulheres e identidades LGBT+ em artigos publicados em diversas editorias neste que é um periódico tradicional e influente, à luz da Teoria das Representações Sociais, como proposta por Denise Jodelet.
\end{abstract}

Palavras-chave: Cinema; Jornais; Lésbicas; Representações.

\section{Resumen}

Este trabajo intenta analizar las representaciones acerca de películas que traen temas lesbianos construidas por el periódico Diario de Pernambuco, de la Ciudad de Recife, Brasil, entre 2016 y principios de 2020, a través de la observación de publicaciones sobre tres películas de temática lesbiana: Carol (2015), dirigida por Todd Haynes, Rafiki (2018), de Wanuri Kahiu y Retrato de una Mujer en Llamas (2019), de Céline Sciamma. Considerando los contextos de producción y recepción de los artículos y de las películas el trabajo procura las representaciones acerca de las identidades femeninas y LGBT+ en este periódico tradicional e influyente en la capital de Pernambuco, analizando artículos de distintos editoriales del periódico mediante la Teoría de las Representaciones Sociales, de Denise Jodelet.

Palabras claves: Cine; Lesbianas; Periódicos; Representaciones.

\footnotetext{
${ }^{1}$ Graduanda em Licenciatura Plena em História, bolsista do Pibic CNPq; Universidade de Pernambuco; Nazaré da Mata, Pernambuco, Brasil; anamaria.histo@gmail.com.

2 Professora Associada; Universidade de Pernambuco; Nazaré da Mata, Pernambuco, Brasil; kalina.silva@upe.br.
} 


\begin{abstract}
This paper aims to analyses representations about movies with lesbian themes elaborated in the Brazilian newspaper Diario de Pernambuco between 2016 and early 2020. To this end, the paper emphasizes articles published simultaneously with the releases of three movies of different nationalities: Carol (2015), directed by Todd Haynes, Rafki (2018), by Wanuri Kahiu and Portrait of a Lady on Fire (2019), by Céline Sciamma. Considering the production and receptions contexts of both the articles and the movies, this paper investigates the representations of women and LGBT+ identities in articles from different editorials of the traditional and influent Brazilian newspaper employing Denise Jodelet's Theory of Social Representations.
\end{abstract}

Keywords: Lesbians; Movies; Newspaper, Representations.

\title{
1. Introdução
}

O presente artigo tem como objetivo analisar as representações construídas pelo jornal recifense Diario de Pernambuco ${ }^{3}$ acerca de filmes com temática lésbica através da análise de matérias publicadas sobre três filmes lançados entre 2015 e 2019: Carol (2015), dirigido por Todd Haynes; Retrato de Uma Jovem em Chamas (2019), sob a direção de Céline Sciamma, e Rafiki (2018), de Wanuri Kahiu. Para alcançar essas representações, traçamos um perfil das matérias publicadas pelo jornal entre 2016 e o primeiro semestre de 2020 que abordam mulheres LGBT+, destrinchando-as através de reflexões sobre produção e recepção de obras cinematográficas segundo Valim (2012) e das análises de representações sociais como propostas por Denise Jodelet.

Se partirmos do princípio que as representações sociais são saberes práticos elaborados e compartilhados socialmente, que são expressões construídas pelos sujeitos de um determinado grupo social com o objetivo de dar sentido à realidade (JODELET, 2001, p.22), percebemos que as matérias publicadas no Diario acerca de mulheres lésbicas são retratos construídos consensualmente pelos profissionais que compõe o periódico, e que desenham imagens acerca dessas protagonistas que não apenas equivalem aos valores sociais do grupo que as elaboram mas também às ideias que esse grupo quer instituir na sociedade. A forma como os jornais constroem suas representações é através das notícias que escolhem publicar e em quais editoriais escolhem publicar essas notícias; se um evento é transformado em notícia política ou policial, ou retratado como cotidiano ou entretenimento depende de como os sujeitos que transformaram o evento em notícia o interpretam. Então, partimos da identificação e quantificação das matérias relacionadas às mulheres lésbicas que foram publicadas nas edições online do Diario de Pernambuco entre 2016 e o primeiro semestre de

\footnotetext{
${ }^{3}$ A palavra "Diario" sem o uso do acento ortográfico é mantida pelo jornal.
} 
2020. Logo, centramos nossa análise nas resenhas de três filmes sobre relacionamentos lésbicos publicadas pelo jornal durante esse período; resenhas que cruzam as representações do periódico pernambucano com aquelas dos diretores dos filmes.

Nesse sentido, é preciso considerar a função que a indústria cinematográfica assume enquanto espaço privilegiado de lutas de representações, com diferentes grupos sociais transformando obras cinematográficas em veículos para seus respectivos sistemas de valores, cada um dos quais busca espaço hegemônico na sociedade. Assim, filmes com temáticas homossexuais podem reiterar discursos heteronormativos através de personagens gays cômicos destituídos de erotismo, ou tecer retratos trágicos elou sensacionalistas, ou fugir dessa heteronormatividade se assumindo queer. O cinema é, dessa forma, um lócus de constantes lutas de representações, de produção de diferentes realidades (BERNARDET, 1980), e, interessado na intimidade dos sujeitos, nas representações de diferentes estilos de vida, ele se torna responsável por promover sentimentos identitários em seus espectadores, principalmente de pertencimento ao grupo social representado (FISCHER, 1996, p.13). Nesse sentido, as representações cinematográficas sobre um determinado tema podem se caracterizar como discursos de verdade, assumindo mesmo a função de uma pedagogia da sexualidade ao apresentar práticas sexuais e de gênero tanto como legítimas quanto como desviantes (LOURO, 2008, p. 82).

As críticas cinematográficas publicadas por periódicos, por seu turno, ao mesmo tempo que são indicativas dos conjuntos de representações aos quais pertencem seus autores, desde o jornalista aos editores responsáveis, também oferecem pistas acerca da recepção dos filmes pelos espectadores. Pois, ao escolher falar sobre uns filmes e silenciar sobre outros, os jornais levam em consideração sua expectativa de um interesse de seus leitores em tais obras. Existe assim uma retroalimentação entre os jornais e seus leitores-espectadores, com os periódicos escolhendo discutir filmes que despertam o que consideram o interesse público e este escolhendo "os filmes pelas representações em revistas, televisão, jornais, conversas e outros contatos sociais" (VALIM, 2012, p. 287).

Nesse sentido, ao nos debruçarmos sobre as matérias que o Diario de Pernambuco dedicou aos três filmes em questão estamos focando tanto as representações hegemônicas nas editorias desse jornal acerca das mulheres lésbicas, construídas a partir das agendas políticas dessa empresa midiática e dos valores dos escritores que nela trabalham, quanto o diálogo que 
o periódico mantém com seu público, com os temas e obras que acredita que seus leitores se interessam por conhecer mais.

\section{O cinema de temática lésbica e suas representações no Diario}

Sediado na cidade de Recife, o Diario de Pernambuco foi fundado em 1825 e é atualmente o jornal mais antigo em circulação na América Latina, como afirma seu slogan, pertencente a um conglomerado que inclui também o jornal Aqui PE, arrendamentos da rádio Clube AM e FM, os portais pernambuco.com, Superesportes PE, Vrum, Lugar Certo, além de sites, redes sociais e aplicativos vinculados. Sua periodicidade é regular, de segunda a sexta, com uma super edição de fim de semana aos sábados, e além da versão impressa disponibiliza também seu conteúdo em formato digital, integralmente para assinantes e parcialmente para o público geral, organizado pelas editorias Opinião, Política, Economia, Brasil, Giro (Mundo), Vida Urbana, DP Esportes (Superesportes) e Viver (DIARIO DE PERNAMBUCO; DP.PRESSLAB).

Periódico com grande influência no Estado de Pernambuco, o Diario vem sendo objeto de estudos há décadas. Com cento e noventa e quatro anos e tendo atravessando contextos históricos diversos sem interromper sua periodicidade, ele se apresenta como uma fonte privilegiada para o estudo da política, mudanças sociais e culturais, assim como as representações sociais na cidade do Recife: “O 'problema das seitas' e os periódicos: uma análise das representações sobre o movimento Hare Krishna nos jornais (1974-1984)" (CARVALHO L., 2019); “As relações de gênero sob o olhar da câmara inocente: imagens e representações do homem e da mulher no Diario de Pernambuco da década de 1920" (AMARAL; NASCIMENTO, 2018).

Trabalhos acadêmicos que analisam a temática LGBT+ no jornal ainda são escassos, encontramos apenas dois: “Tá pensando que travesti é bagunça?’: repertórios sobre travestilidade, em contextos de criminalidade, por jornais de Pernambuco" (CARVALHO B., 2014) e “(In)visibilizando preconceitos: uma análise discursiva sobre casos de violência contra pessoas trans na mídia pernambucana" (KOREY; CALVANCATI; RAMIRES, 2020). Portanto, pretendemos contribuir com essa produção.

As matérias que o Diario de Pernambuco dedica à temáticas LGBT+ refletem o alargamento da esfera pública conquistado pelas mobilizações da comunidade. A tramitação 
de leis que atendam a esse público, atos políticos e manifestações como a Parada da Diversidade, estimulam debates na mídia, especificamente em coberturas jornalísticas, e constroem representações sobre as identidades LGBT+ que alteram a própria linha editorial do Diario de Pernambuco, situação que também dialoga com o aumento do interesse dos leitores do jornal nessas temáticas (ALVES REIS; MAIA, 2006, p.48-57). E para atender esse interesse o jornal articula notícias LGBT+ em diferentes editorias reportando não só violências, mas entretenimento, saúde, política.

No entanto, certos posicionamentos do jornal invisibilizam diferenças dentro dessa comunidade. No Diario, matérias com temática lésbica correspondem a um número menor do que aquelas com temática gay o que está em sintonia com a menor visibilidade das mulheres homossexuais na mídia brasileira, segundo Ferreira "a menor exposição, por mais contraditório que isso pareça, reforça o preconceito a lésbica, dado que fortalece o anonimato, e por tabela a solidão" (FERREIRA, 2017, p. 29). Inclusive o termo gay é, em alguns momentos, utilizado pelo jornal para se referir às mulheres lésbicas e essa atitude reforça a exclusão, ao desconsiderar práticas de gênero diferenciadas para gays e lésbicas (RICH, 2012, p.39). No quadro 1 vemos essa utilização nas matérias "Katy Perry revela que rezou para não ser gay na adolescência" (DP, 21 mar. 2017) e "Atrizes de Orange Is the New Black surpreendem noiva em casamento gay" (AGÊNCIA ESTADO, 2 mar. 2018).

Para o ano de 2016 identificamos os termos 'lésbica', 'lésbico' em catorze manchetes do Diario. ${ }^{4}$ Já nos anos seguintes, até o primeiro semestre de 2020, foram publicadas trinta e nove, contabilizando um total de cinquenta e três manchetes dentro do nosso recorte temporal. O ano de 2016 foi escolhido como marco do nosso recorte porque a partir dele as lésbicas ganham mais representatividade, principalmente local, em oposição ao ano de 2015. Entre os temas dessas matérias vinte e um abordam violência, preconceito e invisibilidade em oposição a trinta e dois, que trazem representações positivas, dando visibilidade às mulheres lésbicas em papéis afirmativos.

Quadro 1 - Matérias negativas sobre lésbicas no Diario de Pernambuco

\footnotetext{
${ }^{4}$ Trabalhamos com a ferramenta de busca Mecanismo de Pesquisa Programável, do Google, para seleção de matérias no acervo digital do Diario de Pernambuco (MECANISMO DE PESQUISA PROGRAMÁVEL). Contabilizamos apenas matérias que tinham como assunto principal a identidade lésbica ou que traziam essa identidade no título.
} 
RELACult - Revista Latino-Americana de Estudos em Cultura e Sociedade

Revista Latinoamericana de Estudios en Cultura y Sociedad | Latin American Journal of Studies in Culture and Society V. 06, $\mathrm{n}^{\circ}$ 03, set-dez., 2020, artigo n⿳0 2018 | claec.org/relacult | e-ISSN: 2525-7870

\begin{tabular}{|c|c|c|c|}
\hline Título & Autor & Seção & Data \\
\hline $\begin{array}{l}\text { Pai é suspeito de tentar } \\
\text { estupro "corretivo" com a } \\
\text { filha de } 14 \text { anos }\end{array}$ & Diario de Pernambuco & Brasil & $13 / 01 / 2016$ \\
\hline $\begin{array}{c}\text { Autor do viral Oração canta } \\
\text { eu sou sapatão e causa } \\
\text { polêmica entre lésbicas }\end{array}$ & Bossuet Alvim - Portal Uai & Viver & $14 / 01 / 2016$ \\
\hline $\begin{array}{l}\text { Médico ofende casal de } \\
\text { lésbicas e diz que 'gays, se } \\
\text { pegar, tem que matar' }\end{array}$ & Agência do Estado & Brasil & $16 / 06 / 2016$ \\
\hline $\begin{array}{l}\text { Casal de lésbicas denuncia } \\
\text { homofobia no CCBB Rio; } \\
\text { instituição afasta funcionária }\end{array}$ & - & Brasil & $02 / 01 / 2017$ \\
\hline $\begin{array}{l}\text { Atriz Bruna Marquezine } \\
\text { revela que já beijou uma } \\
\text { mulher em jogo do Eu Nunca } \\
\text { com Mariana Ximenes }\end{array}$ & Estado de Minas & Viver & $08 / 03 / 2017$ \\
\hline $\begin{array}{l}\text { Líder religioso é suspeito de } \\
\text { estuprar jovem lésbica como } \\
\text { 'cura gay' }\end{array}$ & - & Vida Urbana & $04 / 08 / 2017$ \\
\hline $\begin{array}{c}\text { Katy Perry revela que rezou } \\
\text { para não ser gay na } \\
\text { adolescência }\end{array}$ & Diario de Pernambuco & Viver & $21 / 03 / 2017$ \\
\hline $\begin{array}{c}\text { Globo corta cenas entre } \\
\text { personagens lésbicas de } \\
\text { Senhora do Destino }\end{array}$ & - & Viver & 09/08/2017 \\
\hline $\begin{array}{c}\text { Violência e invisibilidade } \\
\text { marcam realidade de lésbicas } \\
\text { no Brasil }\end{array}$ & - & Brasil & $29 / 08 / 2017$ \\
\hline $\begin{array}{l}\text { Irmãs são confundidas com } \\
\text { lésbicas e denunciam } \\
\text { preconceito em clube }\end{array}$ & Estado de Minas & Brasil & $06 / 11 / 2017$ \\
\hline $\begin{array}{c}\text { Ellen Page se diz alvo de } \\
\text { assédio e homofobia: 'Você } \\
\text { devia transar com ela para } \\
\text { saber se é gay' }\end{array}$ & Diario de Pernambuco & Viver & $13 / 11 / 2017$ \\
\hline $\begin{array}{l}\text { Dossiê mostra crescimento da } \\
\text { violência contra mulheres } \\
\text { lésbicas no Brasil }\end{array}$ & - & Brasil & $08 / 03 / 2018$ \\
\hline $\begin{array}{c}\text { Lésbicas são espancadas por } \\
\text { quatro jovens que queriam } \\
\text { obrigá-las a se beijar }\end{array}$ & Estado de Minas & Mundo & $07 / 06 / 2019$ \\
\hline $\begin{array}{l}\text { Diretor acusa Warner de ter } \\
\text { censurado Velma lésbica em } \\
\text { filme de Scooby-Doo }\end{array}$ & Diario de Pernambuco & Viver & $13 / 07 / 2019$ \\
\hline
\end{tabular}


RELACult - Revista Latino-Americana de Estudos em Cultura e Sociedade

Revista Latinoamericana de Estudios en Cultura y Sociedad | Latin American Journal of Studies in Culture and Society V. 06, $\mathrm{n}^{\circ}$ 03, set-dez., 2020, artigo n⿳0 2018 | claec.org/relacult | e-ISSN: 2525-7870

\begin{tabular}{|c|c|c|c|}
\hline $\begin{array}{c}\text { Beijo lésbico anunciado pela } \\
\text { Globo em 'Órfãos da Terra' é } \\
\text { cortado por 'decisão artística' }\end{array}$ & Folhapress & Viver & $06 / 09 / 2019$ \\
\hline $\begin{array}{c}\text { "Daria super certo", diz Vera } \\
\text { Fischer sobre namorar uma } \\
\text { mulher }\end{array}$ & - & Viver & $24 / 09 / 2019$ \\
\hline $\begin{array}{c}\text { França: conservadores } \\
\text { protestam contra reprodução } \\
\text { assistida de lésbicas e } \\
\text { solteiras }\end{array}$ & AFP & Mundo & $06 / 10 / 2019$ \\
\hline $\begin{array}{c}\text { Casal de mulheres é agredido } \\
\text { durante prévias em Olinda }\end{array}$ & - & Vida Urbana & $20 / 01 / 2020$ \\
\hline
\end{tabular}

Fonte: Site do Diario de Pernambuco.

Quadro 2 - Matérias positivas sobre lésbicas no Diario de Pernambuco

\begin{tabular}{|c|c|c|c|}
\hline Título & Autor & Seção & Data \\
\hline $\begin{array}{l}\text { Seminário discute políticas } \\
\text { públicas para lésbicas e } \\
\text { bissexuais }\end{array}$ & - & Vida Urbana & $01 / 04 / 2016$ \\
\hline $\begin{array}{c}\text { Em Game of Thrones, Sansa } \\
\text { deveria namorar mulheres, } \\
\text { diz Sophie Turner }\end{array}$ & Estado de Minas & Viver & $20 / 05 / 2016$ \\
\hline $\begin{array}{l}\text { Marcha das Lésbicas } \\
\text { reivindica fim da violência } \\
\text { contra as mulheres em SP }\end{array}$ & - & Brasil & $28 / 05 / 2016$ \\
\hline $\begin{array}{l}\text { Diretores comentam } \\
\text { repercussão de possível casal } \\
\text { lésbico em Procurando Dory }\end{array}$ & Diario de Pernambuco & Viver & $09 / 06 / 2016$ \\
\hline $\begin{array}{l}\text { Hospital da Mulher promove } \\
\text { mutirão de atendimento para } \\
\text { lésbicas, bissexuais e trans }\end{array}$ & - & Vida Urbana & $05 / 07 / 2016$ \\
\hline $\begin{array}{l}\text { Hospital da Mulher com } \\
\text { atendimento humanizado } \\
\text { para lésbicas, bissexuais e } \\
\text { trans }\end{array}$ & Carolina Sá Leitão & Vida Urbana & $06 / 07 / 2016$ \\
\hline $\begin{array}{l}\text { Hospital da Mulher realiza } \\
\text { mutirão de saúde para a } \\
\text { população LBT }\end{array}$ & - & Vida Urbana & $06 / 07 / 2016$ \\
\hline $\begin{array}{c}\text { Hospital da Mulher do } \\
\text { Recife faz mutirão para } \\
\text { atendimento de lésbicas, bis } \\
\text { e trans }\end{array}$ & - & Vida Urbana & $07 / 12 / 2016$ \\
\hline
\end{tabular}


RELACult - Revista Latino-Americana de Estudos em Cultura e Sociedade

Revista Latinoamericana de Estudios en Cultura y Sociedad | Latin American Journal of Studies in Culture and Society V. 06, $\mathrm{n}^{\circ}$ 03, set-dez., 2020, artigo n⿳0 2018 | claec.org/relacult | e-ISSN: 2525-7870

\begin{tabular}{|c|c|c|c|}
\hline $\begin{array}{c}\text { Beijo lésbico de Bruna } \\
\text { Marquezine chama a atenção } \\
\text { em Nada Será como Antes }\end{array}$ & Diario de Pernambuco & Viver & $19 / 10 / 2016$ \\
\hline $\begin{array}{c}\text { Mulher, lésbica e agora } \\
\text { prefeita }\end{array}$ & Marcionila Teixeira & Política & $22 / 10 / 2016$ \\
\hline $\begin{array}{l}\text { Lésbicas, bissexuais e trans } \\
\text { poderão ser atendidas sem } \\
\text { marcação de consulta no } \\
\text { Hospital da Mulher }\end{array}$ & - & Vida Urbana & $08 / 03 / 2017$ \\
\hline $\begin{array}{c}\text { Power Rangers apresentará } \\
\text { primeira heroína lésbica de } \\
\text { Hollywood }\end{array}$ & $\begin{array}{l}\text { Portal Uai e Diario de } \\
\text { Pernambuco }\end{array}$ & Viver & $20 / 03 / 2017$ \\
\hline $\begin{array}{l}\text { Malhação exibe beijo lésbico } \\
\text { às vésperas da Parada Gay }\end{array}$ & Diario de Pernambuco & Viver & $16 / 06 / 2017$ \\
\hline $\begin{array}{l}\text { Feijoada e debate antecipam } \\
\text { Dia da Visibilidade Lésbica }\end{array}$ & Ângela Farias & Viver & $25 / 08 / 2017$ \\
\hline $\begin{array}{l}\text { Campanha Chocante é seu } \\
\text { preconceito fortalece } \\
\text { enfrentamento à violência } \\
\text { contra LGBTs }\end{array}$ & - & Vida Urbana & $29 / 08 / 2017$ \\
\hline $\begin{array}{c}\text { Colóquio discute visibilidade } \\
\text { das lésbicas e mulheres } \\
\text { bissexuais }\end{array}$ & - & Vida Urbana & $29 / 08 / 2017$ \\
\hline $\begin{array}{c}\text { Rolê da Visibilidade Lésbica } \\
\text { fará adesivaço nos bares e } \\
\text { polos LGBT }\end{array}$ & - & Vida Urbana & $30 / 08 / 2017$ \\
\hline $\begin{array}{c}\text { Rolê da Visibilidade Lésbica } \\
\text { faz adesivaço nos bares e } \\
\text { polos LGBT }\end{array}$ & - & Vida Urbana & $31 / 08 / 2017$ \\
\hline $\begin{array}{l}\text { Rolê da Visibilidade Lésbica } \\
\text { leva informação de saúde e } \\
\text { cidadania aos bares LGBTs }\end{array}$ & - & Vida Urbana & $01 / 09 / 2017$ \\
\hline $\begin{array}{c}\text { 'O importante é se permitir } \\
\text { amar', diz Giovanna Grigio } \\
\text { sobre beijo lésbico em } \\
\text { Malhação }\end{array}$ & Diario de Pernambuco & Viver & $22 / 12 / 2017$ \\
\hline $\begin{array}{c}\text { Atriz comemora repercussão } \\
\text { de beijo lésbico em } \\
\text { Malhação com frase de } \\
\text { Johnny Hooker }\end{array}$ & Diario de Pernambuco & Viver & $03 / 01 / 2018$ \\
\hline $\begin{array}{l}\text { Beijo lésbico em Malhação } \\
\text { causa comoção nas redes } \\
\text { sociais }\end{array}$ & Diario de Pernambuco & Viver & $03 / 01 / 2018$ \\
\hline
\end{tabular}


RELACult - Revista Latino-Americana de Estudos em Cultura e Sociedade

\begin{tabular}{|c|c|c|c|}
\hline $\begin{array}{l}\text { Atrizes de Orange Is the } \\
\text { New Black surpreendem } \\
\text { noiva em casamento gay }\end{array}$ & Agência Estado & Viver & $02 / 03 / 2018$ \\
\hline $\begin{array}{c}\text { Terça Negra homenageia } \\
\text { Marielle Franco e o Dia } \\
\text { Nacional da Visibilidade } \\
\text { Lésbica }\end{array}$ & Diario de Pernambuco & Viver & $20 / 08 / 2018$ \\
\hline $\begin{array}{l}\text { Hospital da Mulher do } \\
\text { Recife terá tratamento de } \\
\text { hormonização para } \\
\text { população LBT }\end{array}$ & - & Vida Urbana & $24 / 06 / 2019$ \\
\hline $\begin{array}{c}\text { Hospital Agamenon } \\
\text { Magalhães recebe seminário } \\
\text { sobre saúde da população } \\
\text { lésbica e mulher bissexual }\end{array}$ & - & Vida Urbana & $29 / 08 / 2019$ \\
\hline $\begin{array}{c}\text { Militante Íris de Fátima será } \\
\text { primeira lésbica a receber } \\
\text { título de cidadã } \\
\text { pernambucana }\end{array}$ & - & Vida Urbana & $11 / 09 / 2019$ \\
\hline $\begin{array}{c}\text { Reality show de casamentos } \\
\text { com Arlindo Grund terá uma } \\
\text { noiva lésbica }\end{array}$ & Lívia Rosa & Coluna João Alberto & $16 / 09 / 2019$ \\
\hline $\begin{array}{l}\text { Liberem cenas Vamila: fãs } \\
\text { pedem para que Globo } \\
\text { transmita beijo lésbico }\end{array}$ & Diario de Pernambuco & Viver & $19 / 09 / 2019$ \\
\hline $\begin{array}{l}\text { Clube que propõe debate } \\
\text { sobre obras lésbicas chega ao } \\
\text { Recife neste sábado }\end{array}$ & Diario de Pernambuco & Vida Urbana & $10 / 10 / 2019$ \\
\hline $\begin{array}{c}\text { Bogotá elege mulher lésbica } \\
\text { como prefeita pela primeira } \\
\text { vez na história }\end{array}$ & AFP & Mundo & $28 / 10 / 2019$ \\
\hline
\end{tabular}

Fonte: Site do Diario de Pernambuco.

Em muitas dessas matérias, por exemplo ao noticiar uma prefeita lésbica eleita na cidade de Passira no estado de Pernambuco em 2016 (TEIXEIRA, 22 out. 2016), o jornal associa a identidade lésbica à identidade pernambucana, e, visto a importância desta última para o jornal e seu público (PRYSTHON; ROSÁRIO, 2005), essa associação tende para a valorização da identidade lésbica, o que sugere a existência de um significativo público lésbico entre os leitores e assinantes do periódico. E tentando alcançar essas leitoras é que o jornal publicou resenhas de filmes com temática lésbica, como Carol (2015), Rafiki (2018) e Retrato de Uma Jovem em Chamas (2019). 
Quadro 3 - Resenhas de filmes com temática lésbica no Diario de Pernambuco

\begin{tabular}{|c|c|c|c|}
\hline Título & Autor & Seção & Data \\
\hline $\begin{array}{c}\text { Carol representa um novo } \\
\text { passo na representação } \\
\text { cinematográfica da } \\
\text { homossexualidade }\end{array}$ & Júlio Cavani & Viver & \\
\hline $\begin{array}{c}\text { Filme com romance lésbico } \\
\text { volta a chamar atenção em } \\
\text { Cannes }\end{array}$ & Folhapress & Viver & \\
\hline $\begin{array}{c}\text { Drama lésbico desafia leis } \\
\text { do Quênia que criminalizam } \\
\text { homossexuais }\end{array}$ & Folhapress & Mundo & \\
\hline $\begin{array}{c}\text { Esnobado no Oscar Retrato } \\
\text { de Uma Jovem em Chamas } \\
\text { é um filme belo e } \\
\text { necessário }\end{array}$ & Rodolfo Bourbon & Viver & $07 / 05 / 2019$ \\
\hline
\end{tabular}

Fonte: Site do Diario de Pernambuco.

Essas resenhas são textos de opinião, por isso diferem dos gêneros jornalísticos editorial e informativo, primeiro porque levam o nome de seus autores, não representando a opinião do jornal em si, segundo porque não tem nenhuma pretensão à objetividade, abusando do uso de adjetivos e elaborando juízos de valor (GOMES, 2006, p.91-94). Esse é o caso do texto de Rodolfo Bourbon em "Esnobado no Oscar, Retrato de Uma Jovem em Chamas é um filme belo e necessário" (BOURBON, 15 jan. 2020) que além de utilizar uma narrativa em primeira pessoa, é rico em metáforas e ironias.

Duas das resenhas foram fornecidas pela Folhapress do Grupo Folha - conglomerado de mídia brasileiro - ao Diario de Pernambuco: "Filme com romance lésbico volta a chamar atenção em Cannes" (FOLHAPRESS, 20 mai. 2019) e "Drama lésbico desafia leis do Quênia que criminalizam homossexuais" (FOLHAPRESS, 7 ago. 2019). Segundo Freire (2018, p. 53), a utilização de informações de agências de notícias é uma estratégia dos jornais para poupar dinheiro e tempo, agilizando o trabalho dos jornalistas. Os textos de opinião foram publicados originalmente no site do jornal Folha de São Paulo com os mesmos títulos (GENESTRI, 20 mai. 2019; GABRIEL, 7 ago. 2019). Citamos a Folhapress e não os autores ao longo da análise pois estamos utilizando como fonte as versões disponibilizadas no Diário de Pernambuco, e vale ressaltar que as matérias originais não estão abertas ao público, o site 
do jornal limita quantas vezes se pode acessar suas notícias. Também são comuns publicações de jornais parceiros em seu site, como do Estado de Minas e do Correio Braziliense. Mas é importante notar que, mesmo que não tenham sido escritas em Pernambuco, o fato de o Diario ter comprado essas matérias reflete sua crença de que as mesmas falariam ao seu público de leitores.

Quanto às editorias dos textos publicados, três estão na seção Viver, especializada em textos voltados à cultura, entretenimento, artes, e um deles na seção Mundo que noticia acontecimentos fora do Brasil. Sobre Carol, a matéria de título "Carol representa um novo passo na representação cinematográfica da homossexualidade", publicado em 14/01/2016 na editoria Viver foi escrita por Júlio Cavani, diretor de curtas metragens, para divulgar o lançamento do filme no Brasil. O subtítulo apresenta as atrizes, Cate Blanchett e Rooney Mara, a relação amorosa entre ambas e o nome do diretor, abaixo há uma foto de divulgação da distribuidora Mares Filmes na qual as personagens principais trocam olhares, acompanhada de uma legenda sobre a ambientação do filme na década de 50, e sua plasticidade visual. $\mathrm{O}$ artigo utiliza uma linguagem direcionada aos cinéfilos, com termos como "plasticidade visual" e descrições da estética como "ornamentada pela Arte Nouveau", sem explicar seus significados; presumindo que o público da seção Viver, e mais especificamente daqueles que leem matérias sobre filmes no jornal, estão familiarizados com os conceitos e termos técnicos da indústria cinematográfica.

A trama do filme se centra no romance entre Therese, uma jovem inexperiente, e Carol, uma mulher mais velha, casada e em processo de divórcio, e tem como pano de fundo os Estados Unidos da década de 1950. O romance vai se desenrolando, retratado a partir de troca de olhares e toques, até que a relação é descoberta, o que leva Carol a se separar de Therese para não ser exposta publicamente pelo ex-marido. Ambas voltam a se reencontrar no final do filme, o que sugere um possível recomeço, mas não exclui o temor e a preocupação excessiva das personagens com as normas sociais. Ao longo de uma hora e quarenta minutos de filme as personagens são constantemente vigiadas precisando provar para namorado, exmarido e até desconhecidos a inexistência de um relacionamento romântico. Carol, por exemplo, é questionada em vários momentos pelo ex-marido Harge do porquê ser tão próxima de Therese que acabara de conhecer e da amiga, e ex-namorada, Abby. Harge também usa esse passado com Abby e uma fita de áudio provando o romance com Therese para conseguir a guarda da filha, sob o pretexto de atentado à moralidade. A fala do advogado de defesa de Carol expõe que ela passou por diversos terapeutas e médicos renomados que provaram sua 
aptidão de cuidar da filha e a superação dessa "falência emocional". Apenas nos quinze minutos restantes há um posicionamento mais forte das personagens: Carol desiste de disputar a guarda da filha para que o marido desista de levar o caso aos tribunais, afirmando não se arrepender do romance pois faz parte de quem ela é, o amadurecer de Therese e o reencontro das personagens.

A matéria do Diario apresenta Carol como a obra com o maior potencial transformador dentre os lançamentos do Oscar daquele ano por transmitir "de forma verdadeira" o amor das personagens a ponto de sensibilizar todos os tipos de espectadores, sem os "falsos moralismos" vistos em alguns filmes de temática homossexual. Mas reconhece que o filme continua a retratar a relação amorosa das personagens como tabu, sem a naturalização dos romances heterossexuais (CAVANI, 14 jan. 2016). E contradições como essa permeiam o artigo: já no título há a apresentação do filme como revolucionário, por romper com as representações da homossexualidade até então vistas no cinema, uma afirmação, entretanto, que desconsidera não apenas todo o New Queer Cinema na década de 90 nos Estados Unidos (BALTAR, 2015) como a heteronormatividade da obra. Além disso, a resenha desconsidera as relações de poder associadas às diferenças de gênero dentro dá própria experiência gay e lésbica, obscurecendo o feminismo e as particularidades especificas das mulheres do grupo (RICH, 2012, p.39): esse obscurecimento pode ser visto no artigo, por exemplo, quanto ele compara Carol a outros longas de temática homossexual, mas usa como contraponto o filme $O$ segredo de Brokeback Mountain (2005), romance gay dirigido por Ang Lee, com homens como protagonistas, silenciando sobre outros filmes de temática lésbica.

As representações ambíguas continuam na manchete, seguida de still do filme e legenda que não dialogam: na foto, as personagens trocam olhares em uma loja de departamento, mas a legenda diz "Trama é ambientada na década de 1950, com forte plasticidade visual". A legenda silencia, assim, o erotismo da imagem e enquanto esta sugere um romance entre as mulheres, o texto joga o foco sobre questões técnicas do filme. E essa posição, que quer ao mesmo tempo confortar tanto um público lésbico quanto um público conservador, continua ao longo do artigo: logo no primeiro parágrafo o autor elogia o poder que o filme possui de criar empatia para com as protagonistas até nos espectadores "mais conservadores" visto que "O amor entre as lésbicas interpretadas por Rooney Mara e Cate Blanchett é transmitido de forma tão verdadeira que é praticamente impossível alguém ver o filme sem torcer para elas ficarem juntas" (CAVANI, 14 jan. 2016). Um discurso conciliatório que apresenta uma suposição pessoal do autor como fato: que todos os 
espectadores vão receber o filme da mesma forma, o que contradiz as definições mais básicas de recepção cinematográfica que preveem que diferentes espectadores interpretam de formas distintas cada obra cinematográfica a depender de suas experiências pessoais, identidades, além dos sistemas de valores aos quais pertencem (BERNARDET, 1980, p. 19). Além disso, minimiza a homofobia ao sugerir que as reações negativas do público conservador a outras obras com temática lésbica seria o resultado simplesmente de tramas apresentadas de forma menos 'verdadeira'.

Ao longo do texto, esse discurso conciliatório se desenrola em enunciados como aquele onde o autor elogia as escolhas do diretor Todd Haynes que "permitem que a homossexualidade seja retratada sem tantos riscos de falsos moralismos". Aqui a expressão "sem tantos" sugere que em filmes dessa temática seriam aceitáveis alguns falsos moralismos, desde que não excessivos. Mais à frente, ao afirmar que "A condição das personagens, contudo, ainda é retratada na tela como um tabu, sem a naturalização normalmente vista em histórias sobre heterossexuais", o autor defende que essa "condição", ou seja, orientação sexual das protagonistas, não é o fator mais importante na trama e sim o "afeto e o respeito", acima de "qualquer conflito" (CAVANI, 14 jan. 2016). Nesse sentido, o artigo reduz a identidade lésbica das protagonistas a uma 'condição', palavra frequentemente associada ao discurso médico que afirma a homossexualidade como uma patologia (GUIMARÃES, 2009). Isso no mesmo enunciado que critica a falta de naturalidade das representações cinematográficas de relacionamentos gays e lésbicos. Por outro lado, ao afirmar que o mais importante da trama é o afeto, a despeito de qualquer conflito e da própria identidade das protagonistas, o discurso procura apaziguar o público conservador, apresentando assim uma justificativa para o romance entre as mulheres. Esse discurso também supõe que o respeito prevalece sobre qualquer conflito pessoal, quando alude à desistência do marido em expor Carol, o que teria encerrado o "conflito" do divórcio e disputas pela guarda da filha.

Quatro anos depois, o jornal deu espaço à divulgação de outros dois filmes com temática lésbica: Rafiki, filme de 2018, produzido no Quênia e o francês Retrato de Uma Jovem em Chamas (2019) dirigido por Celine Sciamma, em duas republicações da Folhapress. A primeira, dedicada ao Retrato..., é intitulada por "Filme com romance lésbico volta a chamar atenção em Cannes", publicada em 20/05/2019. Abaixo da manchete há uma fotografia das protagonistas, sem créditos de autoria, que mostra uma tocando a outra no rosto, ambas reagindo ao toque de olhos fechados. Aqui percebemos, ao comparar com as resenhas de Rafiki e Carol, a padronização das representações fotográficas das mulheres 
lésbicas: nas três matérias as cenas escolhidas para ilustrar as obras retratam as protagonistas em situações ternas, trocando olhares e toques, em situações delicadas.

Nas duas matérias do Viver sobre o filme Retrato de Uma Jovem Em Chamas, da diretora francesa Céline Sciamma, 2019, o foco é no olhar feminino e na perspectiva feminista do longa. Outras matérias, dentro do nosso recorte temporal, dialogam com o feminismo no cinema ao criticar a falta de filmes com protagonismo e direção feminina, divulgando aqueles que são representativos e criando uma ligação entre os textos e as identidades de leitoras pernambucanas feministas em busca por representatividade cinematográfica. É o caso dos artigos "Ponto de vista masculino domina as telas do cinema, constata pesquisa" (ESTADO DE MINAS, 2 out. 2017) e "Mulheres virão com tudo no audiovisual em 2019" (IZEL; CORREIO BRAZILIENSE, 18 dez. 2018). No caso da matéria sobre Retrato... já no início do texto a Folhapress afirma que desde o movimento feminista \#metoo o Festival de Cannes começou a ser questionado por dar pouca representatividade a diretoras mulheres, ao que teria respondido com "obras marqueteiras e de pouca substância". Para a Folhapress, Retrato de Uma Jovem em Chamas não é uma dessas, pois dá representatividade para tais grupos "sem sacrificar a consistência e cumprir cota" no festival. O artigo apresenta o contexto da obra - a Bretanha no século XVII -, as atrizes, seus respectivos papéis e o desenrolar da trama: Marianne (Noémie Merlant) é contratada para pintar às escondidas um quadro de Hélöise (Adèle Haenel) que deveria ser um presente ao rico milanês a quem fora prometida. Com Marianne fingindo ser dama de companhia de Hélöise enquanto pinta seu retrato, o romance entre as duas se desenrola.

A cineasta, segundo o artigo, usa as obras elaboradas por diferentes retratistas para analisar as diferenças não apenas entre a arte produzida por mulheres daquela produzida por homens, mas também as formas opostas como personagens femininas são representadas em filmes dirigidos por homens daqueles dirigidos por mulheres. Para ressaltar esse ponto, o artigo compara o filme Le Jeune Ahmed (2019), de Jean-Pierre e Luc Dardenneque, que então disputava a Palma de Ouro de Cannes com Retrato de Uma Jovem em Chamas, enfatizando como os Dardenneque não conseguem, da mesma forma que Sciamma, adentrar a realidade do protagonista, diferente da sua (FOLHAPRESS, 20 mai. 2019). Nessa mesma perspectiva está também a comparação com Azul É a Cor Mais Quente, dirigido por Abdellatif Kechiche, e vencedor da Palma de Ouro no Festival em 2013: um outro filme que retrata uma relação lésbica, mas vista a partir de um olhar masculino com as personagens e sua reação moldadas de acordo com o desejo masculino. 
Laura Mulvey (2018) afirmou, em texto hoje clássico, que o olhar masculino, quando aposto à obra de arte, impõe um controle sob os corpos de mulheres exibidas, objetificando-as para atender aos desejos masculinos, enquanto no olhar feminino são as próprias mulheres que criam significados em torno de seus corpos, seus desejos e vontades. Segundo essa perspectiva, o fato de ser dirigido por uma mulher, não conter personagens homens e exibir o amor entre duas mulheres, torna Retrato de Uma Jovem Em Chamas exemplar do olhar feminino na cinematografia. Sua trama expõe rotinas e saberes elaborados por mulheres retratistas, amantes, mães, filhas, serviçais, curandeiras, dentre outras que coexistem com uma realidade opressiva. Para a Folhapress o olhar feminino se expressa também na equidade do desejo: Marianne e Helöise olham e desejam, ao mesmo tempo são objeto dos olhares e "Ao final, não se sabe se a garota em chamas do título é que é objeto do retrato e que será rifada em casamento ou se é a que o pinta e que está consumida pelo desejo" (FOLHAPRESS, 20 mai. 2019).

Mas apesar desse elogio ao olhar feminino do filme, a matéria dedica quase tanto espaço à presença masculina em Cannes do que à obra de Sciamma: em primeiro lugar por também elaborar uma sinopse do filme Le Jeune Ahmed, em segundo por usar a opinião do diretor Xavier Dolan para atribuir valor a Retrato...: reproduzindo trecho de fala de Dolan, quando este afirma que "Me senti confortável, tanto romântica quanto psicologicamente diante da ausência de personagens homens" (FOLHAPRESS, 20 mai. 2019), a matéria usa a fala masculina para legitimar um filme feminino; constrói assim uma representação na qual a competência feminina precisa ser corroborada por um julgamento masculino. Da mesma forma, a fala masculina parece ‘dar permissão' para a existência de um filme sem personagens homens.

Além disso, a resenha cria uma representação dicotômica entre o olhar feminino, delicado, e o olhar masculino, voyeur, mas, diferente das teses de Mulvey (1989 apud MALUF; MELLO; PEDRO, 2005, p.345), distingue esses olhares não pelo tipo de abordagem construídos nas obras, mas simplesmente pelo gênero de seus diretores: segundo a resenha, a obra de Sciamma demonstraria uma "delicadeza" e uma "feminilidade" presentes em outros filmes como Tomboy (2010) e Garotas (2014) em oposição ao "registro voyeur de Abdellatif Kechiche" (FOLHAPRESS, 20 mai. 2019).

A matéria sobre Retrato... também direciona seu discurso para um público cinéfilo: ao colocar no título "Cannes" desacompanhado da palavra "Festival", a agência de notícias 
direciona seu conteúdo aquele público especializado que sabe associar a cidade francesa, Cannes, com o muito prestigiado festival de cinema internacional. O título do filme está em francês, Portrait de la Jeune Fille en Feu, porque no momento da publicação da matéria ele não tinha uma distribuidora brasileira - é ela quem decide qual título vai circular no país. $\mathrm{O}$ filme só veio a ser lançado no Brasil em 9 de janeiro de 2020. O texto também presume que seus leitores estão atualizados com as notícias internacionais, especialmente aquelas de cunho feminista, ao fazer referência ao \#metoo, que alude ao movimento iniciado pelo discurso da atriz Asia Argento no Festival de Cannes em 2018, acusando o cineasta Harvey Weinstein de abuso sexual e que desencadeou uma campanha quando a atriz Alyssa Milano estimulou mulheres que sofreram algum tipo de abuso e assédio sexual a responderem pelo Twitter utilizando a hashtag. A partir de então outros grandes nomes da indústria cinematográfica foram envolvidos em denúncias (BBC NEWS BRASIL, 2018).

Já a resenha sobre Rafiki, "Drama lésbico desafia leis do Quênia que criminalizam homossexuais", foi publicada no Diario em 07/08/2019 na editoria Mundo. Colocar a notícia nesta editoria subestima o potencial do filme de entreter os leitores do jornal para expor seu lado político, já que o contexto queniano é repressivo para homossexuais. Sugere a crença do jornal de que a obra pode não agradar seus leitores de entretenimento, talvez por fazer parte de um cinema pouco conhecido comparado ao norte-americano, latino-americano e europeu. Abaixo do título há uma foto de divulgação sem legenda ou créditos onde as protagonistas, Kena e Ziki, trocam olhares enquanto riem.

O texto da matéria informa que Rafiki fez história, não apenas por ser o primeiro filme queniano a participar do Festival de Cannes, mas por ser uma história LGBT contextualizada no país. Enfatiza o 'fazer história' como elemento de valorização da obra, inclusive através da entrevista da atriz Sheila Munyiva, que interpreta Ziki, sobre a representatividade do filme para a comunidade LGBT do Quênia. Logo após essa ênfase no lugar do filme como marco histórico, a matéria apresenta o enredo e as personagens: na cidade de Nairobi, Ziki e Kena (Samantha Mugatsia) desenvolvem um relacionamento amoroso em meio à homofobia e às querelas políticas de suas famílias. Logo, a resenha passa a historicizar a legislação queniana que criminaliza a homossexualidade, o posicionamento do atual presidente sobre direitos LGBT, a proibição do longa metragem no país e, por fim, a superação da diretora que recorreu à Justiça para exibir o filme pelo tempo mínimo de sete dias que lhe permitiria ser elegível para o Oscar. 
O artigo atribui ao filme também uma função na construção das identidades: ao reproduzir trechos da entrevista de Munyiva na qual a atriz relata o papel deletério que a falta de representações televisivas positivas de mulheres africanas teve na construção da sua identidade, criando uma analogia com o papel que o filme assume na criação de identidades positivas lésbicas para a nova geração queniana. Segundo Munyiva, “"Rafiki' será capaz de fazer o mesmo para pessoas da comunidade LGBT. Isso permitirá que se sintam vistos, lindos, amados, ouvidos e, mais importante, pertencentes."” (FOLHAPRESS, 7 ago. 2019). Ou seja, para os autores da matéria o filme se apresenta como um veículo de legitimação da identidade lésbica em uma região de extrema negação dessa identidade, e um veículo de produção de um sentimento positivo de pertencimento à mesma.

As representações dominantes no texto, assim, são de monumentalização do filme e de severa crítica à homofobia do Quênia. Nesse sentido, afirma já na manchete que o filme quer desafiar o Código Penal do país, que prescreve longas sentenças para o que considera “conjunção carnal não natural". A matéria se apresenta assim como uma denúncia à homofobia institucionalizada queniana, derivada, sugere o artigo, do colonialismo: "Desde 1897, quando o Quênia ainda era uma colônia, a homossexualidade é criminalizada. Em maio deste ano, o Supremo Tribunal local julgou a possibilidade de abolição dessas leis, mas a proposta acabou rejeitada" (FOLHAPRESS, 7 ago. 2019).

Por outro lado, se o reconhecimento de um contexto queniano pela Folhapress e o lugar de fala da atriz na notícia são contrapontos ao senso comum ocidental que homogeneíza o continente africano e esquece de suas particularidades, por outro, a matéria não explora essas particularidades. Não foge, por exemplo, da narrativa ocidental que vê a África como um todo enquanto local de "homofobia excessiva" nem da representação que justifica intervenções internacionais no continente africano, desconsiderando contextos específicos de cada um deles e deslegitimando lutas queer africanas, que não são consultadas (EKINE, 2016, p. 10 e 13$)$.

$\mathrm{O}$ artigo da Folhapress Diario, assim, ao mesmo tempo que insiste que o filme "desafia" a homofobia queniana, não aprofunda nem as realidades da produção da obra, nem do movimento LGBT+ queniano. A diretora do filme, por exemplo, afirmou em entrevistas concedidas em Cannes que nunca teve o objetivo de desafiar nada; segundo el País "Kahiu não é militante de nenhuma causa. Nega que haja qualquer provocação em seu projeto. 'Só adaptamos um livro que já contava essa história', afirma a cineasta[...]" (VICENTE, 13 mai. 
2018). Ela, além disso, tenta fugir das representações negativas acerca da África, centradas em imagens de doença e tristeza, contrastando tais imagens com representações de amor, através da plataforma Afro Bubble Gum voltada para promoção de uma representação frívola da África (VICENTE, 13 mai. 2018). Nesse sentido, a intenção da autora do filme diverge consideravelmente da representação proposta pela matéria republicada no Diario.

Mas é certo que, independentemente das intenções originais artísticas da diretora, a recepção da obra pelo governo queniano e pelo público internacional constituem uma verdadeira luta de representações em torno do filme que é espelhada pela matéria do Diario. A matéria, ao focar a questão da representatividade positiva do filme versus a homofobia em torno de seu lançamento, também reflete mais as preocupações sociais brasileiras do que necessariamente as quenianas.

Se o primeiro artigo sobre o Retrato... foi publicado por oportunidade do lançamento do filme em Cannes, a segunda matéria foi publicada em 15/01/2020, na mesma semana do lançamento no Brasil, intitulada "Esnobado no Oscar, Retrato de Uma Jovem em Chamas é um filme belo e necessário", de autoria do editor da seção Viver no Diario de Pernambuco, Rodolfo Bourbon. Ocupando uma posição de prestígio dentro da redação de um jornal, Bourbon tem uma liberdade maior para publicar seus textos. Sua decisão, assim, por resenhar esse filme, após a publicação da matéria concomitante com o festival, espelha a recepção da mesma pelo público leitor de sua editoria. Uma recepção que pode ser vista também no fato de que, diferente das três notícias anteriores, esta foi publicada também na versão impressa do Diario, na edição de 15/01/2020 com o título "Mulheres em chamas".

A matéria é composta pelo texto escrito, duas fotografias e um trailer. As fotografias foram fornecidas pela distribuidora Supo Mungam Films: uma repete aquela presente na matéria anterior e a outra corresponde a uma cena do filme na qual as protagonistas estão em primeiro plano, ambas esboçando comoção enquanto Marianne toca Helöise no rosto e ela apoia mãos e braços no tronco de Marianne, tendo como fundo uma praia. $\mathrm{O}$ trailer legendado foi disponibilizado pelo canal ingresso.com no Youtube, essa escolha provavelmente leva em consideração a legitimidade da empresa, a primeira ticketeria online no Brasil, e não deixa de ser uma divulgação da marca para os leitores. No final há as tags ou rótulos relacionados ao texto: "Retrato de Uma Jovem em Chamas, Céline Sciamma, filme, crítica, resenha" (BOURBON, 15 jan. 2020), auto identificando o texto como uma resenha crítica do filme. 
As imagens obedecem ao padrão já discutido de escolha de cenas nas quais as protagonistas apenas se tocam e se entreolham. Mas a inclusão do trailer amplia o escopo das representações do artigo, já que através do mesmo o leitor tem acesso a toda a complexidade visual e conteudista da obra. E em termos de ideias escritas o artigo aprofunda a matéria anterior: nele o autor começa afirmando que seu texto não será sobre "as injustiças cometidas pelo Oscar", porém que é inevitável não sentir a ausência de Retrato de Uma Jovem Em Chamas nas indicações. Além disso, antes de apresentar o filme, traz um breve histórico de premiações e presenças do longa-metragem em diversos festivais de cinema, enfatizando a escassez de diretoras mulheres indicadas ao prêmio de Melhor Direção em 2020 e o fato de que tal situação não era uma novidade. Posteriormente diz ser o foco da filmografia de Céline Sciamma o protagonismo feminino, citando outros de seus filmes, ao mesmo tempo resume o enredo, tece comentários, cita passagens do filme, de falas das personagens e dialoga com os leitores. Conclui afirmando a competência de Sciamma e sua aptidão para premiação como o Oscar, contrapostas à ausência de representatividade feminina entre os diretores premiados por este "que em 92 edições só consagrou uma diretora: Kathryn Bigelow, por Guerra ao terror, em 2010" (BOURBON, 15 jan. 2020, grifo do autor).

Dois temas ganham forma no texto: o menosprezo do filme pelo Oscar em 2020, explicado pela falta de representatividade de diretoras nas indicações de Melhor Direção ao longo dos anos, e o porquê de Retrato de Uma Jovem em Chamas merecer premiações em grandes eventos. Diferente das outras matérias, o título não deixa claro qual a temática do filme, ressalta as características "belo e necessário", sem enfatizar que se trata de um romance lésbico. Nesse sentido, o autor naturaliza o romance, atribuindo maior importância à falta de representatividade feminina no Oscar. Também chama atenção a narrativa em primeira pessoa e a informalidade do autor: "Este texto, prometo, não irá se aprofundar no corriqueiro debate das injustiças cometidas pelo Oscar. [...] Eita, descumpri novamente a promessa. Tipo o Oscar, que sempre promete mais representatividade" (BOURBON, 15 jan. 2020). Uma informalidade que espelha uma familiaridade presumida entre o autor e os leitores.

Ao compararmos a data de estreia do filme, com as de divulgação dos indicados ao Oscar e da notícia do Diário de Pernambuco, respectivamente 09, 13 e 15 de janeiro de 2020, percebemos que ela foi escrita dois dias depois da divulgação das indicações à premiação norte-americana, o que explica o inconformismo do autor pela ausência de Retrato... na premiação: expressões como "injustiças cometidas pelo Oscar", " uma das mais contundentes ausências", "sequer disputa como Melhor Filme Internacional" (BOURBON, 15 jan. 2020), 
enfatizam esse sentimento no primeiro parágrafo. E para legitimar o valor da obra, o autor cita outras premiações conquistadas por ela em diferentes festivais de cinema.

Ao informar que o filme de Sciamma estreou "junto com Adoráveis mulheres, dirigido por Greta Gerwig" e em seguida que "nenhuma mulher concorre a melhor direção no Oscar", o autor destaca que existem outros filmes dirigidos por mulheres no ano de 2019 escanteados pelo Oscar. Em seguida afirma: "Não é novidade. Por sinal, nos últimos dez anos, apenas uma vez, entre 50 chances, uma mulher figurou entre os candidatos na maior categoria individual. E foi justamente Greta, com Lady bird, em 2018” (BOURBON, 15 jan. 2020, grifos do autor). Na passagem "apenas uma vez, entre 50 chances" o autor está se referindo a quantia de cinco indicados por categoria no Oscar, ou seja, em dez anos as mulheres tiveram 50 chances de indicações ao prêmio de Melhor Direção, porém apenas Gerwig conseguiu em 2018; a expressão "nos últimos dez anos" indica proximidade com 2020, e significa que não houveram tantos esforços do Oscar para mudar essa ausência. Uma estagnação cuja exposição culmina na informação sobre o prêmio de Melhor Direção de Kathryn Bigelow, único entre as diretoras. Ao dizer que o Oscar "sempre promete mais representatividade", mas não cumpre Bourbon se refere às inúmeras acusações que o evento tem sofrido em anos anteriores e que retornaram com a hashtag \#OscarsSoMale (\#OscarÉMuitoMasculino), nas redes sociais com o lançamento das indicações em 2020. O autor não está se referindo à falta de representatividade feminina em outras indicações no Oscar, apenas ao prêmio de Melhor Direção. Essa tomada de posição baseia-se no reconhecimento de uma hierarquia na produção de filmes encimada pelo papel do diretor. Sendo assim o Oscar está dando um lugar secundário a mulheres em indicações menos importantes, ao invés de uma posição de prestígio.

Para Bourbon o filme de Sciamma "é belo e forte" e essa "força" estaria nas mulheres dos filmes dirigido por Céline Sciamma: "Enquanto desnuda fragilidades e opressões, a diretora sempre evidencia a força das mulheres” (BOURBON, 15 jan. 2020). Ao citar outras obras de Céline Sciamma, como também fez o Folhapress, Bourbon promove Tomboy (2011) e Garotas (2014), e suas representações. Essas representações fortes e belas seriam assim as responsáveis por tornar Retrato de Uma Jovem em Chamas em um filme "necessário", atribuição dada pelo autor no título da matéria. Os autores das resenhas sobre o filme reconhecem e enfatizam as conexões feitas pela diretora entre as identidades lésbica e feminista. Em uma obra na qual as protagonistas desafiam representações fixas associadas às mulheres, à heterossexualidade compulsória se opõem atitudes, escolhas e opiniões fortes, e 
ao retratar um relacionamento lésbico livre de julgamentos o filme se enquadra não apenas como feminista, mas também como queer.

\section{Conclusão}

Em todas essas matérias vemos um jogo de representações que querem ser simpáticas às identidades lésbicas, mas que muitas vezes caem na conciliação com discursos conservadores, ou simplesmente reproduzem imagens congeladas das mulheres submissas, erotizadas ou secundarizadas. Apenas o texto de autoria de um editor traz uma visão que naturaliza o romance entre mulheres e se preocupa mais com questões da indústria artística do que com a exotização da sexualidade lésbica; enquanto o texto de um diretor, homem, de cinema, termina reproduzindo o discurso conciliatório com conservadores, e os da agência de notícia reproduzem um olhar masculino comum nas representações cinematográficas ocidentais.

E tais representações elaboradas por um olhar masculino são predominantes; afinal, os únicos artigos assinados, são de autoria de homens. Então, apesar de pregar a relevância do protagonismo feminino no cinema, em sua própria estrutura o jornal não o pratica.

\section{Referências}

ALVES REIS, R.; MAIA, R. Do pessoal ao político-legal: estratégias do jornalismo para enquadrar os movimentos gays. Revista FAMECOS: mídia, cultura e tecnologia, vol., n.30, p.46-61, 30 ago. 2006. ISSN: 1415-0549. Disponível em:

https://www.redalyc.org/articulo.oa?id=495550186005. Acesso em: 30 set. 2020.

AMARAL, T. L.; NASCIMENTO, A. C. do. As relações de gênero sob o olhar da câmara inocente: imagens e representações do homem e da mulher no Diario de Pernambuco da década de 1920. Caicó, v. 18, n. 40, p. 12-36, 15 abr. 2018. ISSN: 1518-3394. Disponível em: https://www.periodicos.ufrn.br/mneme/article/view/12221/9336. Acesso em: 30 set. 2020.

BALTAR, M. Femininos em tensão: da pedagogia sociocultural a uma pedagogia dos desejos. In: MURALI, L.; NAGIME, M. (Orgs.). Meu Queer Cinema - Cinema, sexualidade e política. São Paulo: Caixa Econômica Federal, 2015. p. 42-47. 
BBC NEWS BRASIL. O que a campanha \#MeToo conseguiu mudar de fato?. BBC NEWS BRASIL, Brasil, 21 mai. 2018. Disponível em: https://www.bbc.com/portuguese/geral44164417. Acesso em: 23 ago. 2020.

BERNARDET, Jean-Claude. O que é cinema. São Paulo: Editora brasiliense, 1980. (Coleção Primeiros Passos, $\mathrm{n}^{\circ}$ 9).

BOURBON, R. Esnobado no Oscar, Retrato de Uma Jovem em Chamas é um filme belo e necessário. Diário de Pernambuco online, Recife, 15 jan. 2020. Seção Viver. Disponível em: https://www.diariodepernambuco.com.br/noticia/viver/2020/01/esnobado-no-oscar-retrato-deuma-jovem-em-chamas-e-um-filme-belo-e-ne.html. Acesso em: 19 de mar. 2020.

CAROL. Direção de Todd Haynes. Estados Unidos: Killer Films, The Weinstein Company, Film4 Productions, Number 9 Films, StudioCanal, 2015. $118 \mathrm{~min}$.

CARVALHO, B. R. de B. “Tá pensando que travesti é bagunça?”: repertórios sobre travestilidade, em contextos de criminalidade, por jornais de Pernambuco. 2014. $126 \mathrm{f}$. Dissertação (Mestrado em Psicologia) - CFCH, Universidade Federal de Pernambuco, Recife. 2014. Disponível em: https://repositorio.ufpe.br/handle/123456789/10286. Acesso em: 4 set. 2020.

CARVALHO, L. A. G. de. O "problema das seitas" e os periódicos: uma análise das representações sobre o movimento Hare Krishna nos jornais (1974-1984). Cadernos De História, v. 19, n. 31, p. 213-233, 30 mai. 2019. ISSN: 2237-8871. Disponível em: https://doi.org/10.5752/P.2237-8871.2018v19n31p213. Acesso em: 4 set. 2020.

CAVANI, J. Carol representa um novo passo na representação cinematográfica da homossexualidade. Diário de Pernambuco online, Recife, 14 jan. 2016. Seção Viver. Disponível em: https://www.diariodepernambuco.com.br/noticia/viver/2016/01/carolrepresenta-um-novo-passo-na-representacao-cinematografica-da-hom.html. Acesso em: 19 de mar. 2020.

EKINE, S. NARRATIVAS CONTESTADORAS DA ÁFRICA QUEER. Trad. Sob a direção de Caterina Rea. Cadernos de Gênero e Diversidade, vol. 02, n. 02, p. 10-14, jul./dez. 2016. ISSN 2525-6904. Disponível em: http://dx.doi.org/10.9771/cgd.v2i2.20727. Acesso: 03 set. 2020 .

ESTADO DE MINAS. Ponto de vista masculino domina as telas do cinema, constata pesquisa. Diário de Pernambuco online, Recife, 02 out. 2017. Seção Viver. Disponível em: 
https://www.diariodepernambuco.com.br/noticia/viver/2017/10/ponto-de-vista-masculinodomina-as-telas-do-cinema-constata-pesquisa.html. Acesso em: 19 mar. 2020.

FERREIRA, S. A. S. (et al.). Homossexualidade Feminina, Liberdade Sexual e Interiorização do Ensino Superior. Cadernos de Gênero e Diversidade, vol. 03, n. 02, p. 27-47, mai./ ago. 2017. ISSN: 2525-6904. Disponível em: http://dx.doi.org/10.9771/cgd.v3i2.22090. Acessado em: 19 mar. 2020.

FISCHER, R. M. B. Adolescência em discurso: Mídia e produção de subjetividade. 1996. 297 f. Tese (Doutorado em Educação) - Faculdade de Educação, Universidade Federal do Rio Grande do Sul, Porto Alegre. 1996. Disponível em: https://lume.ufrgs.br/handle/10183/10281. Acessado em: 23 out. 2020.

FOLHAPRESS. Filme com romance lésbico volta a chamar atenção em Cannes. Diário de Pernambuco online, Recife, 20 mai. 2019. Seção Viver. Disponível em: https://www.diariodepernambuco.com.br/noticia/viver/2019/05/filme-com-romance-lesbicovolta-a-chamar-atencao-em-cannes.html. Acesso em: 19 mar. 2020.

FOLHAPRESS. Drama lésbico desafia leis do Quênia que criminalizam homossexuais. Diário de Pernambuco online, Recife, 07 ago. 2019. Seção Mundo. Disponível em: https://www.diariodepernambuco.com.br/noticia/mundo/2019/08/drama-lesbico-desafia-leisdo-quenia-que-criminalizam-homossexuais.html. Acesso em: 19 mar. 2020.

FREIRE, F. L. As transformações nas rotinas produtivas das redações: Diário de Pernambuco e Jornal do Commercio. 2018. 152 f. Dissertação (Mestrado em Comunicação) - Centro de Artes e Comunicação, Universidade Federal de Pernambuco, Recife. 2018.

Disponível em: https://repositorio.ufpe.br/handle/123456789/30442. Acesso em: 23 out. 2020.

GABRIEL, C. Drama lésbico desafia leis do Quênia que criminalizam homossexuais. Folha de São Paulo, São Paulo, 7 ago. 2019. Seção Ilustrada. Disponível em: https://www1.folha.uol.com.br/ilustrada/2019/08/drama-lesbico-desafia-leis-do-quenia-quecriminalizam-homossexuais.shtml. Acessado em: 13 ago. 2020.

GENESTRI, G. Filme com romance lésbico volta a chamar atenção em Cannes. Folha de São Paulo, São Paulo, 20 mai. 2019. Seção Ilustrada. Disponível em:

https://www1.folha.uol.com.br/ilustrada/2019/05/filme-com-romance-lesbico-volta-a-chamaratencao-em-cannes.shtml. Acessado em: 13 ago. 2020. 
GOMES, V. S. História do editorial jornalístico em Pernambuco: aspectos formais e funcionais desta tradição discursiva. In: CIAPUSCIO, G. et. al. (Ed.). Sincronía y diacronía de tradiciones discursivas em Latinoamérica. Madrid-Frankfurt: Iberoamericana-Vervuert, 2006. p. 83-99.

GUIMARÃES, A. F. P. O desafio histórico de "tornar-se um homem homossexual": um exercício de construção de identidades. Temas em Psicologia, vol. 17, n. 2, p. 553-567, 2009. ISSN: 1413-389X. Disponível em: https://www.redalyc.org/articulo.oa?id=513751434023. Acesso em: 20 set. 2020.

IZEL, A.; CORREIO BRAZILIENSE. Mulheres virão com tudo no audiovisual em 2019. Diário de Pernambuco online, Recife, 18 dez. 2018. Seção Viver. Disponível em: https://www.diariodepernambuco.com.br/noticia/viver/2018/12/mulheres-virao-com-tudo-noaudiovisual-em-2019.html. Acesso em: 19 mar. 2020.

JODELET, D. Representações Sociais: um domínio em expansão. In: JODELET, D. (Org.). As Representações Sociais. Trad. Sob a direção de Lilian Ulup. Rio de Janeiro: Ed. UERJ, 2001. p. 17-44.

KOREY, P.; CAVALCANTI, R. M.; RAMIRES, V. M. (In)visibilizando preconceitos: uma análise discursiva sobre casos de violência contra pessoas trans na mídia pernambucana. Revista Diálogos, v. 8, n. 1, p. 175-194, 28 abr. 2020. ISSN: 2319-0825. Disponível em: https://periodicoscientificos.ufmt.br/ojs/index.php/revdia/article/view/9393. Acesso em: 30 set. 2020.

LOURO, G. L. Cinema e Sexualidade. Educação \& realidade, vol. 33, n. 1 p. 81-97, jan./jun. 2008. ISSN: 2175-6236. Disponível em:

https://seer.ufrgs.br/educacaoerealidade/article/view/6688/4001. Acesso em: 20 mar. de 2020.

MALUF, S. W.; MELLO, C. A. de; PEDRO, V. Políticas do olhar: feminismo e cinema em Laura Mulvey. Estudos Feministas, v.13, n. 2, p. 343-350, mai./ago. 2005. ISSN 1806-9584. Disponível em: http://dx.doi.org/10.1590/S0104-026X2005000200007. Acesso em: 19 mar. 2020.

MULVEY, L. Prazer Visual e Cinema Narrativo: Interligando feminismo, psicanálise e cinema. Trad. Sob a direção de Ariana Amara. QG Feminista - Medium, 27 abr. 2018. Disponível em: https://medium.com/qg-feminista/prazer-visual-e-cinema-narrativo9749dd27e616. Acesso em: 19 mar. 2020. 
Publicação digital do Diario de Pernambuco pelo software Presslab (DP.PRESSLAB). Disponível em: https://dp.presslab.com.br/. Acesso em: 30 set. 2020.

PRYSTHON, A.; ROSÁRIO, A. T. do. Manguetown: identidade, cultura e geografia no jornalismo cultural impresso. Comunicação e Informação, v. 8, n. 1, p. 47 - 52, jan./jun. 2005. ISSN: 1415-5842. Disponível em: https://doi.org/10.5216/c\&i.v8i1.24594. Acesso em: 19 mar. 2020.

RAFIKI. Direção de Wanuri Kahiu. Quênia, África do Sul, França, Holanda, Alemanha: Big World Cinema, Awali Entertainment, MPM Film, Rinkel Film, Razor Film Produktion, APE\&BJØRN, 2018. 83 min.

RETRATO de Uma Jovem em Chamas. Direção de Céline Sciamma. França: Lilies Films, Hold Up Films, Arte France Cinema, 2019. 119 min.

RICH, A. Heterossexualidade compulsória e existência lésbica. Trad. Sob a direção de Carlos Guilherme do Valle. Bagoas, v.4, n.05, p.17-44, 27 nov. 2012. ISSN: 2316-6185. Disponível em: https://periodicos.ufrn.br/bagoas/article/view/2309/1742. Acesso em 30 mai. 2020.

Site do Diario de Pernambuco. Disponível em: https://www.diariodepernambuco.com.br/. Acessado em: 30 set. 2020.

Site do Mecanismo de Pesquisa Programável. Disponível em:

https://programmablesearchengine.google.com/about/. Acessado em: 30 set. 2020.

VALIM, A. B. História e Cinema. In: CARDOSO, C. F.; VAINFAS, R. (Orgs.). Novos Domínios da História. Rio de Janeiro: Elsevier, 2012. p. 283-300.

VICENTE, A. “Que ninguém veja meu filme, porque colocará minha vida em perigo”. El País, Brasil, 13 mai. 2018. Disponível em: https://brasil.elpais.com/brasil/2018/05/13/cultura/1526208196_776906.html. Acesso: 04 set. 2020. 